\title{
SSR Polymorphism Survey between CRMS31A and Aruna (MO8) for Marker Assisted Backcross Breeding in Rice
}

\author{
T.S. Lachyan ${ }^{1 *}$, V.G. Jayalekshmy ${ }^{1}$ and Swapna Alex ${ }^{2}$ \\ ${ }^{1}$ Department of Plant Breeding and Genetics, ${ }^{2}$ Department of Plant Biotechnology, College of \\ Agriculture, Kerala Agricultural University, India \\ *Corresponding author
}

\section{A B S T R A C T}

\section{Keywords}

Cytoplasmic male sterility,

Polymorphic,

Simple Sequence

Repeats (SSR),

Foreground

selection,

Background

Article Info

Accepted:

26 October 2019

Available Online:

10 November 2019
SSR polymorphism in two rice varieties viz., CRMS31A (donor parent cytoplasmic male sterile line) and Aruna (high yielding, short duration variety with long, bold red grain. tolerant to $\mathrm{BPH}$, medium resistant to stem borer and sheath root) was investigated to identify ready to use SSR markers which can be employed in selection of the marker assisted breeding programmes involving these varieties. A total of 115 simple sequence repeat (SSR) primers which were distributed on all the twelve chromosomes of rice were utilized. The results revealed distinct polymorphism among the $\mathrm{cms}$ and red rice parents for $20 \mathrm{RM}$ primers. Based on this study, the large range of similarity and dissimilarity values for CRMS31A and Aruna provides greater confidence for the assessment of simple sequence repeat (SSR) polymorphism. Diversity analysis can be done by using these polymorphic SSR markers. In this study, PCR-based marker was used for distinguishing male sterile line from maintainer line. Results showed that $\mathrm{cms}$ marker had ability to differentiate male sterile line CRMS31A and Aruna (maintainer).This is helpful in promotion of hybrid seed production technology in Kerala state of India which is main consumer of bold-red rice.

\section{Introduction}

Production and productivity of rice, a staple food for over half of the world's population and is insufficient for the increasing population. Availability of umpteen numbers of molecular markers after completion of rice genome sequencing opened new avenues to better understand the complex traits. As of now, as many as 8000 QTLs governing various traits have been identified and flanking/tightly linked/functional markers for these traits can be used to transfer into elite varieties through MAS. However, identification of background markers for each pair of donor and recipient parental varieties is very laborious and time consuming also. Hence, the present investigation was carried 
out to identify ready to use SSR markers for background selection of a pair of popular donor and recipient variety.

One of the readily available and economically viable technological options for meeting the projected global demand of rice is exploitation of heterosis through large-scale cultivation of rice hybrids. Among the CMS lines used for development of three line rice hybrids, lines based on WA cytoplasm originally derived from a wild rice are the most popular in all countries where hybrid rice is cultivated on a commercial scale.

The first step in a breeding program is careful selection of plant materials to be used as parents to develop a variety with desirable characteristics. There exists a tremendous genetic diversity among the rice crop which easily facilitates improvement in rice. Therefore, breeders are presented with a wide option of parental materials to be selected for crop improvement (Guimara es, 2009). The major objective of plant breeding is to develop high yield potential, desirable agronomic characteristics like high yield improved grain and eating quality and resistance to biotic and abiotic stress, so it is of great importance to breed high- hybrid rice with high yield to feed the growing worldwide population, and here comes the role of CMS where in Cytoplasmic male sterility (CMS) is the foundation for the exploitation of the heterosis of hybrid rice. The 3-line system utilizes a cytoplasmic male sterile (CMS) line, whose multiplication is managed by using a maintainer line. Usually, the CMS line and its corresponding maintainer are genetically very close siblings, differing only in the loci responsible for controlling flower and pollen behaviour.

Frisch et. al. (1999) suggested that molecular markers can be used in backcross breeding for two purposes: (1) To trace the presence of a target allele suggested by Hospital and Charcosset (1997); and (2) to identify individuals with a low proportion of undesirable genome from the donor parent, which by Tanskley et al., (1983) and later reviewed by Viescher et al., (1996). The main advantage of using DNA markers is to accelerate the fixation of recipient alleles in non-target regions and to identify the genotypes containing crossovers close to target genes Tanskley et al.(1989).

\section{Materials and Methods}

Two rice varieties viz., CRMS31A and Aruna constituted the experimental material. Das in 2017 has reported Aruna as potential maintainer line on the basis of pollen fertility and spikelet fertility test. $F_{1}$ progeny of the cross between CRMS 31A and Aruna has shown $0.58 \%$ pollen fertility and $100 \%$ spikelet sterility.

CRMS31A, a cytoplasmic male sterile line was used as the donor of male sterility. It was developed, evaluated and released by scientists in India by National Rice Research Institute (NRRI), Cuttack. The breeder seeds of donor parent were obtained from NRRI, Cuttack. Whereas Aruna is high yielding, short duration variety with long, bold red grain. It is also tolerant to BPH, medium resistant to stem borer and sheath rot. Breeder seeds of Aruna were collected from Regional Research station KAU, Moncompu, Alleppy. These two rice lines were screened with 115 SSR markers to identify polymorphic makers between them. Since they are iso-nuclear, it is not possible to distinguish CMS and maintainer lines before flowering; so a mitochondrial WA-CMSspecific marker (drrcms) developed by Rajendrakumar et al., (2007) was also used to study the polymorphism between the parental lines.

Genomic DNA of the two rice varieties was extracted by CTAB method Murray and Thompson, (1980). Young leaves were selected for extraction of the genomic DNA. 
$0.1 \mathrm{~g}$ of leaves was used with DNA extraction buffer $(1.5 \%$ CTAB, $0.2 \mathrm{M}$ Tris $\mathrm{HCl}, 0.02 \mathrm{M}$ EDTA, $1.4 \mathrm{M} \mathrm{NaCl}$ ) and quality and quantity of extracted DNA was judged by agarose gel electrophoresis. DNA quantification and purity was checked by spectrophotometer. For studying the parental polymorphism between CRMS31A and Aruna, a total of 170 SSR markers were used. The information regarding chromosomal location and sequences of primers were obtained from www.gramene.org.

The purity of DNA was measured by spectrophotometer. $5 \mu 1$ of DNA dissolved in $0.1 \mathrm{X}$ TAE buffer was added to $295 \mu \mathrm{l}$ of distilled water in a cuvet, forming a total volume of $300 \mu \mathrm{l}$ and then absorbance at 260 $\mathrm{nm}$ and $280 \mathrm{~nm}$ was read against distilled water as blank, using UV spectrophotometer. The ratio of absorbance values of DNA at 260 $\mathrm{nm}$ and $280 \mathrm{~nm}$ gives the quality of DNA. The concentration of DNA in the sample was calculated using the formula;

Amount of DNA ng/ml $=(A 260 \times$ Volume of dist.water $(\mu l) \times 0.05 x$

Where, $\mathrm{A} 260=$ Absorbance at $260 \mathrm{~nm}$.

The polymerase chain reaction was carried out in Eppendorf thermal cycler using 170 SSR markers. The PCR reaction of $10 \mu 1$ was set up using 40-50 $\mathrm{ng} / \mu \mathrm{l}$ template DNA, $1 \mu 1$ of $10 \mathrm{mM}$ dNTPs; $1 \mu 1$ of $2.5 \mathrm{mM} \mathrm{MgCl} 2,1 \mu 1$ of 10X Taq Buffer (without $\mathrm{MgCl} 2$ ), $0.5 \mu \mathrm{l}$ of 10 pmoles each of forward and reverse primers and $0.2 \mu \mathrm{l}$ of $5 \mathrm{U}$ Taq DNA polymerase (Genei Pvt. Ltd., India).

The PCR programme included a) initial denaturation at $94^{\circ} \mathrm{C}$ for $5 \mathrm{~min}$, b) denaturation at $94^{\circ} \mathrm{C}$ for $\left.1 \mathrm{~min}, \mathrm{c}\right)$ primer annealing $52.8-64.9^{\circ} \mathrm{C}$ for $1 \mathrm{~min}, \mathrm{~d}$ ) extension $72{ }^{\circ} \mathrm{C}$ for $1 \mathrm{~min}$, e) final extension $72^{\circ} \mathrm{C}$ for 7 min, and f) hold at $4^{\circ} \mathrm{C}$ for $\infty$. Steps from b) to d) were repeated for 35 times for amplification of DNA. After completion of amplification, PCR products were stored at $-20^{\circ} \mathrm{C}$ and the amplified products were analysed by electrophoresis using $2.5 \%$ agarose gel. $3 \mu \mathrm{l} / 100 \mathrm{ml}$ Ethidium bromide was added while pouring the gel so that the DNA fluorescence could be observed when gel was exposed to UV light. The DNA fragments were then visualised under Gel Doc and the banding pattern was observed and recorded using gel documentation unit.

\section{Results and Discussion}

When purity of DNA was measured by spectrophotometer by taking the ratio of UV absorbance at OD260/OD280 was 1.83 and 1.8 for CRMS31A and Aruna respectively. The quantity of DNA in these samples was $550 \mathrm{ng} / \mu \mathrm{l}$ for CRMS31A and $450 \mathrm{ng} / \mu \mathrm{l}$ for Aruna.

PCR was performed with drrcms marker using the template DNA from CMS line (CRMS31A), its isonuclear maintainer line

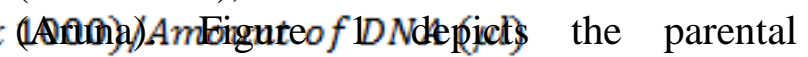
polymorphism by cms specific marker. This marker distinguished CMS line from maintainer line, by producing fragments of 130-bp in the CMS line and a 142-bp band in maintainer line. The amplification of bands was similar to the findings of Rajendrakumar et al., (2007). Ghaffar Kiani (2016) used PCRbased marker to distinguish five male sterile lines (Neda A, Nemat A, Dasht A, Champa A and Amol-3 A) from other five maintainer lines.

Parental polymorphism at the molecular level was determined by genotyping them with SSR markers. Initially the annealing temperature of all the 170 SSR markers was standardized using gradient PCR followed by screening of the genomic DNA of the CRMS 31A sand Aruna using 170 Rice Microsatellites (RM) markers, which were distributed throughout 
the genome over the twelve chromosomes of rice.

The number of bands varied from one to four in the different RM markers of two parents in parental polymorphism study. The size of amplicons resolved among the RM markers ranged from 35bp (RM1038) to 250bp (RM481). Out of the 115 RM markers, 20 were observed to be polymorphic (Table 1) between CRMS31A (WA-CMS parent) and Aruna (cms recipient parent). Among these, three RM markers were on Linkage Group 1 (LG-1), single marker on LG -2, two markers on LG-3, two markers on LG-4, two markers on LG-6, two markers on LG-7, two markers on LG-8, two markers on LG-9, single marker on LG -10, single marker on LG -11 and two markers on LG-12 (Fig. 1). Parental polymorphism per cent between any two parents depended on the number of relevant primers selected for screening. The parental survey revealed 17.39 per cent polymorphism between the two parents used in the present study.

Similar to the findings of the present study, Ahmadikhah et al., (2015) had identified 43polymorphic SSR markers by using 100 SSR markers with 30 per cent polymorphism in IR68897A, maternal CMS donor and Yosen B line, which is a potential maintainer line. Whereas Raghvendra and Hittalmani (2018) used 96 polymorphic SSR marker to develop a potential male sterile line for the production of promising hybrids suitable for aerobic conditions with $44 \%$ parental polymorphism.

Neeraja et al., (2007) used 32 markers in background selection for developing submergence tolerance in rice. Oliveira et al., (2008) also used only 20 markers ( $<2$ markers per chromosome) in MABC program in common bean (Phaseolus vulgaris L.) and Carneiro et al., (2010) used only 25 markers distributed on nine of 11 chromosomes in background selection for improving resistance to white mold in common bean. Yadav et al., (2015) selected 70 polymorphic markers among 500 SSR markers for a cross between BPT-5204 and ARC-10531 rice varieties. Vikram et al., (2011) used 880 SSR markers and reported 71 polymorphic SSR markers with 8.07 per cent polymorphism between two rice varieties, Basmati334 and Swarna.

Salunkhe et al., (2011) studied 343 SSR markers and found 96 SSR markers to be polymorphic between two parents IR20 and Nootripathu with 27.99 per cent parental polymorphism. Similarly, Kanagaraj et al., (2010) also worked on same rice varieties as Salunkhe et al., and reported 134 polymorphic SSR markers out of 1206 SSR markers with 11.12 per cent polymorphism.

The 20 rice microsatellite (SSR) markers identified as polymorphic between the two parents in this `study and it will be useful as a pointer to the existence of different alleles at each of the 20 marker loci.

Further experiments can be performed by utilizing these ready to use polymorphic markers for incorporation of cytoplasmic male sterility into the variety Aruna by marker assisted breeding. The 20 polymorphic markers can be used for background selection and drrms marker can be used for foreground selection of the cross CRMS 31A x Aruna during marker assisted backcross programmes. As CRMS31A, is a cytoplasmic male sterile line, which was used as the donor of cytoplasmic male sterility and Aruna is high yielding, short durated, bold red rice variety of Kerala with tolerance to Brown Plant Hopper and medium resistance to stem borer and sheath rot, there are chances for development of line showing $100 \%$ sterility with BPH tolerance \& some resistance to stem borer and sheath rot. Moreover, these identified polymorphic markers can be used for diversity analysis and linkage analysis for various traits in rice (Fig. 2-4). 
Table.1 Polymorphic SSR markers used for background genotypic analysis of cross between CRMS 31A x Aruna

\begin{tabular}{|l|l|l|l|l|}
\hline $\begin{array}{l}\text { Sr. } \\
\text { no. }\end{array}$ & Locus & Chr. No. & $\begin{array}{l}\text { Annealing } \\
\text { Temp. }\left({ }^{\circ} \mathbf{C}\right)\end{array}$ & $\begin{array}{l}\text { Position on } \\
\text { chromosome (cM) }\end{array}$ \\
\hline $\mathbf{1}$ & RM 481 & 7 & 55 & 3.2 \\
\hline $\mathbf{2}$ & RM 5638 & 1 & 64.9 & 86 \\
\hline $\mathbf{3}$ & RM 1038 & 3 & 62.8 & 62.2 \\
\hline $\mathbf{4}$ & RM 1124 & 11 & 60 & 19.8 \\
\hline $\mathbf{5}$ & RM 285 & 9 & 55 & 1.8 \\
\hline $\mathbf{6}$ & RM 17 & 12 & 55 & 109.1 \\
\hline $\mathbf{7}$ & RM 490 & 1 & 55 & 51 \\
\hline $\mathbf{8}$ & RM 125 & 7 & 55 & 24.8 \\
\hline $\mathbf{9}$ & RM 514 & 3 & 55 & 158.2 \\
\hline $\mathbf{1 0}$ & RM 1019 & 8 & 52.8 & 0.5 \\
\hline $\mathbf{1 1}$ & RM 5708 & 10 & 59 & 23.66 \\
\hline $\mathbf{1 2}$ & RM 1067 & 1 & 61.7 & 181.1 \\
\hline $\mathbf{1 3}$ & RM 266 & 2 & 55 & 192.2 \\
\hline $\mathbf{1 4}$ & RM 217 & 6 & 55 & 38.5 \\
\hline $\mathbf{1 5}$ & RM 280 & 4 & 55 & 128.9 \\
\hline $\mathbf{1 6}$ & RM 1026 & 9 & 61 & 102.3 \\
\hline $\mathbf{1 7}$ & RM 5637 & 8 & 59 & 78.5 \\
\hline $\mathbf{1 8}$ & RM 5633 & 4 & 60 & 63 \\
\hline $\mathbf{1 9}$ & RM 247 & 12 & 55 & 12 \\
\hline $\mathbf{2 0}$ & RM 136 & 6 & 55 & 51.2 \\
\hline
\end{tabular}

Fig.1 Validation of cms gene in donor parent (CRMS31A) and in recurrent parent Aruna with PCR based mitochondrial WA-CMS specific marker.

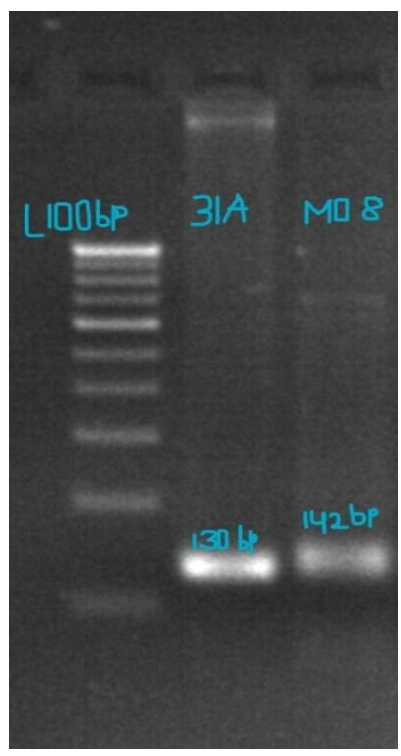


Int.J.Curr.Microbiol.App.Sci (2019) 8(11): 2555-2563

Fig.2 Parental polymorphism shown by RM 5637

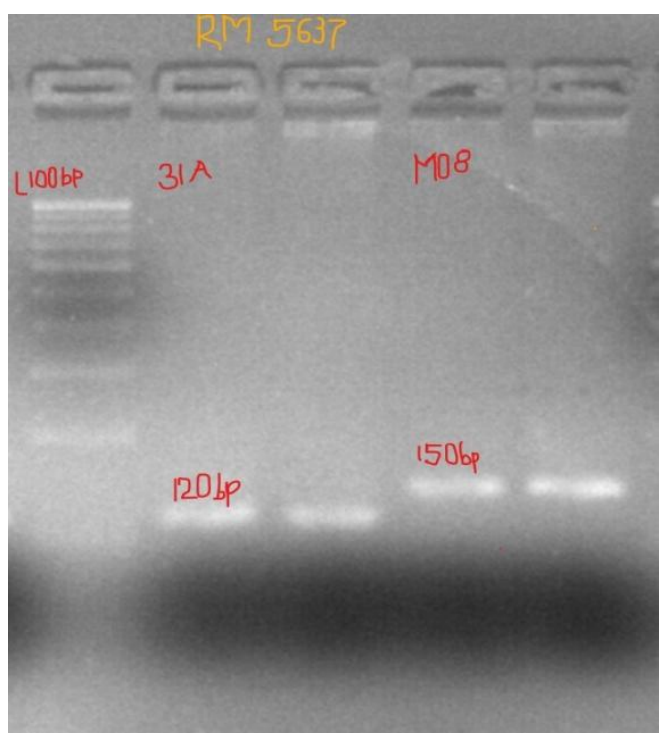

Fig.3 Parental polymorphism shown by RM 1038

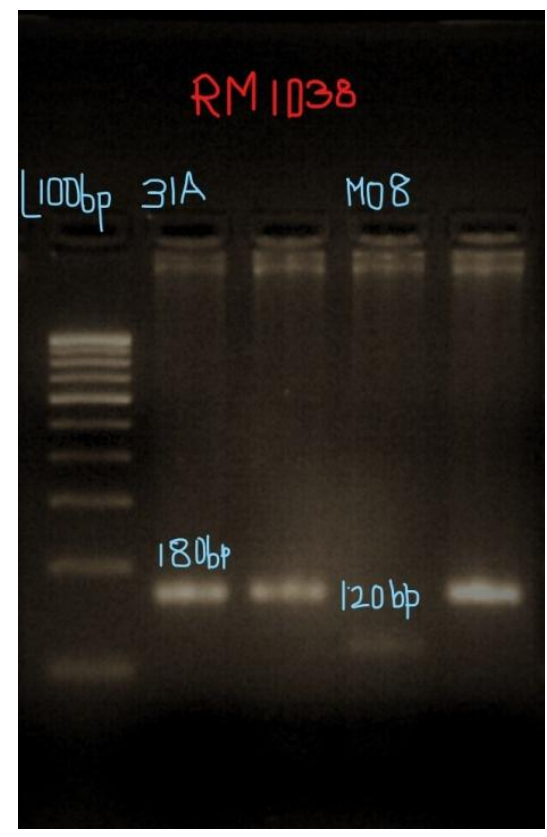


Fig.4 Chromosomal positions of 20 SSR markers selected in this study. Marker name and their positions (in $\mathrm{cM}$ ) are shown at left and right respectively.

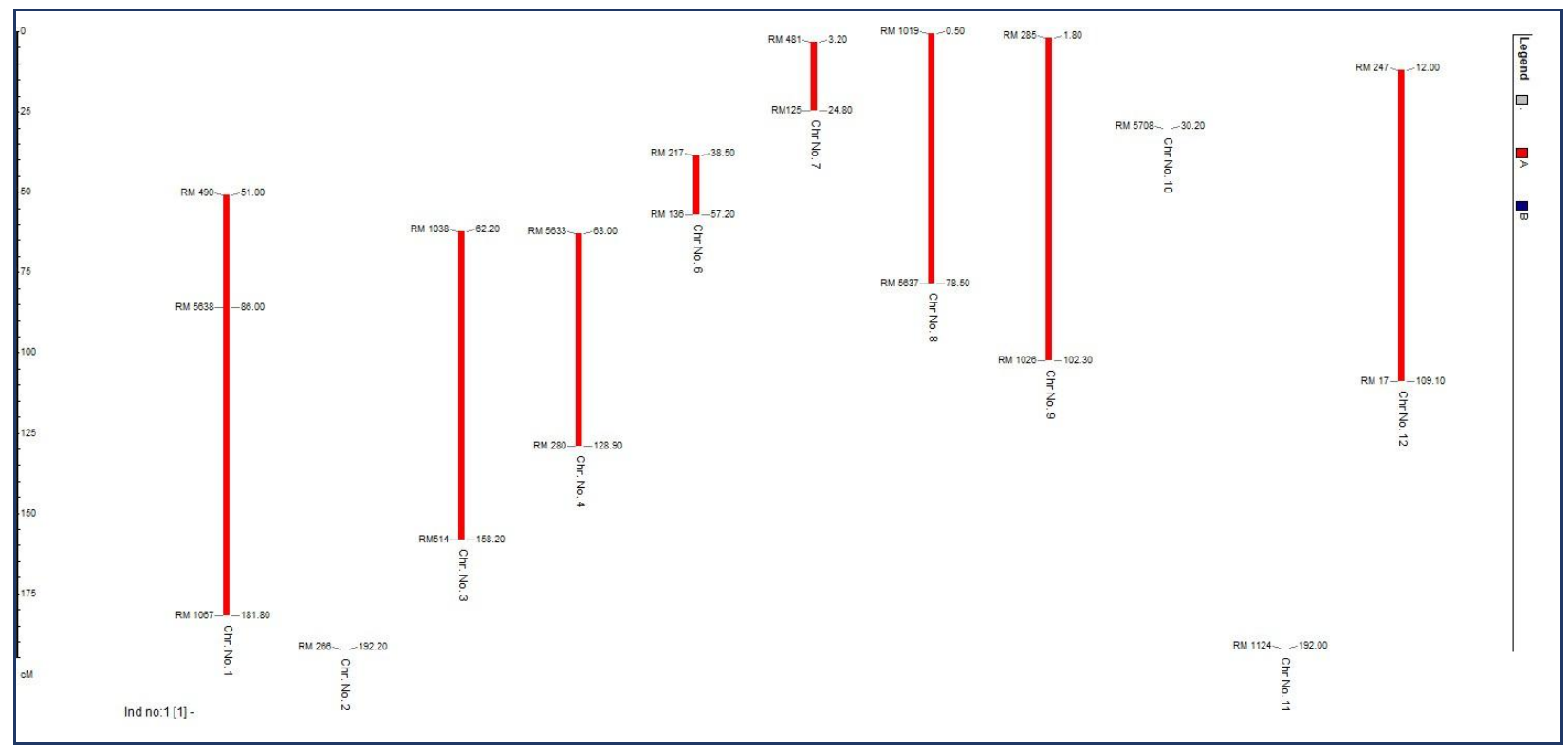

It is concluded, as these markers covering major portion of rice genome, they have wide applications in assessing genetic diversity and also for development of cultivars specific allele profiles of major varieties. At present, a marker of choice is microsatellite or simple sequence repeat (SSR) because it is cost effective and widely used in most rice breeding programs. Moreover it is most suitable for small laboratories with limited resources in developing countries. Of which Class I SSRs with evenly distribution may be of particular applicability in MAS studies owing to their abundance, genome coverage, and high polymorphic nature.

Developing a standard set of microsatellite markers enables researchers from different laboratories to directly compare and share their data, preventing duplication of efforts and facilitating collaborative work among laboratories. The addition of new highly polymorphic markers to sparse regions in the chromosome would enhance the capability of the RMs in MAS programs. The ready to use markers especially common polymorphic markers between different donor groups and recipients identified in the present investigation are of premium value to become a standard set of markers which can be shared by the scientific community of common interests.

\section{Acknowledgement}

Authors gratefully acknowledge COA, Vellayani, Kerala Agricultural University for providing the fund $\&$ facilities to carry out this research programme and are thankful to Regional Agricultural Research Station, Pattambi \& Moncompu, and CRRI, Cuttack for providing seed materials to carry out this research programme.

\section{References}

Ahmadikhah, A, Mirarab M., Pahlewani M., and Nyyeripasand L. 2015. Marker- 
Assisted Backcrossing To Develop And Elite Cytoplasmic Male Sterility Line In Rice. The Plant Genome 8(2): 1-12.

Carneiro, F.F., J.B. Santos, and M.E. Leite. 2010. Marker-assisted backcrossing using microsatellites and validation of SCAR Phs marker for resistance to white mold in common bean. Electron. J. Biotechnol. 13(6):1-8.

Frisch, M. M., Bohn, M., and Melchinger, A. E. 1999. Comparison of selection strategies for marker-assisted backcrossing of a gene. Crop Sci. 39: 1295-1301.

Ghaffar Kiani. 2016. Application of PCRbased Markers for off-type Detection in Rice CMS Lines. Jordan Journal of Agricultural Sciences. 12(4):11931198.

Guimaraes, E. P. 2009. Rice breeding. In: Carena M J (ed.), Cereals, the Bank and the Italian Economy. Springer, New York. pp. 99-126.

Hospital, F., and Charcosset, A. 1997. Marker-assisted introgression of quantitative trait loci. Genetics 147: 1469-1485.

Kanagaraj, P., Prince, K. S. J., Sheeba, J. A., Biji, K. R., Paul, S. B., Senthil, A., and Babu, R. C. 2010. Microsatellite markers linked to drought resistance in rice (Oryza sativa L.). Curr. Sci. 98: 836-839.

Murray, M. G., and Thompson, W. F. 1980. Rapid isolation of high molecular weight plant DNA. Nucleic acids res. 8(19): 4321-4326.

Neeraja, C.N., R. Maghirang, A. Pamplona, S. Heuer, B.C. Collard, E.M. Septiningsih, G. Vergara, D. Sanchez, K. Xu, A.M. Ismail and D.J. Mackill (2007) A marker-assisted backcross approach for developing submergencetolerant rice cultivars. Theor. Appl. Genet., 115 : 757-776.
Oliveira, L.K., L.C. Melo, C. Brondani, M.J.D. Peloso, and R.P.V. Brondani. 2008. Backcross assisted by microsatellite markers in common bean. Genet. Mol. Res. 7: 1000-1010.

Raghvendra, P., and Hittalmani, S. 2018. Novel male sterile line development through marker-assisted backcross breeding suitable for aerobic planting in rice. Journal of Environmental Bioliogy, 38: 277-285.

Rajendrakumar, P., A. K. Biswal, S. Balachandran, M.S. Ramesha, B.C. Viraktamath, and R.M. Sundaram. 2007. A mitochondrial repeat specific marker for distinguishing wild abortive type cytoplasmic male sterile rice lines from their cognate isogenic maintainer lines. Crop Sci. 47:207-211.

Rajib Das, 2017. Genotyping of $R f$ (Restoring Fertility) loci of rice varieties of Kerala using molecular markers. Thesis. Kerala Agricultural University.

Salunkhe, A., Poornima, R., Prince, K. S. J., Kanagaraj, P., Sheeba, J. A., Amudha, K., Suji, K. K., Senthil, A., and Babu, R. C. 2011. Fine mapping QTL for drought resistance traits in rice (Oryza sativa L.) using bulk segregant analysis. Mol. Biotechnol. 49: 90-95.

Tanksley, S.D. 1983. Molecular markers in plant breeding. Plant Mol Biol Rep. 1: $1-13$.

Tanskley, S. D., Young, N. D., Paterson, A. H. and Bonierbale, M. W. 1989. RFLP mapping in plant breeding: New tools for an old science. Biotechnology 7: 257-264.

Viescher, P. M., Haley, C. S., and Thompson, R. 1996. Marker assisted introgression in backcross breeding programs. Genetics 144: 1923-1932.

Vikram, P., Swamy, B. P. M., Dixit, S., Ahmed U. H., Cruz, M. T. S., Singh, A. K., and Kumar, A. 2011. qDTY1.1 a major QTL for rice grain yield under 
reproductive-stage drought stress with a consistent effect in multiple elite genetic backgrounds. BMC Genet. 12: 89.

Yadav, S., Anuradha, G., Kumar, R. R., Vemireddy, L. R., Sudhakar, R., and
Donempudi, K. 2015. Identification of QTLs and possible candidate genes conferring sheath blight resistance in rice (Oryza sativa L.). Springer Plus 4: 175.

\section{How to cite this article:}

Lachyan, T.S., V.G. Jayalekshmy and Swapna Alex. 2019. SSR Polymorphism Survey between CRMS31A and Aruna (MO8) for Marker Assisted Backcross Breeding in Rice. Int.J.Curr.Microbiol.App.Sci. 8(11): 2555-2563. doi: https://doi.org/10.20546/ijcmas.2019.811.295 